\title{
Supplementary Methods and Results
}

\section{Characterization of water sample photo-reactivity}

NOM characteristics of SW basin samples

The chemical characteristics of natural organic matter (NOM) in a lake largely depend on the trophic status and the catchment area features. NOM characteristics change over time and during seasons, which may strongly affect bacterial community composition (BCC). Especially in the upper, illuminated water layers, photochemical reactions generate toxic compounds

21 including reactive oxygen species (ROS) $[1,2,3,4]$. In order to compare NOM concentrations and reactivity between experimental periods, water samples were obtained on $2^{\text {nd }}$ July $2006,5^{\text {th }}$

23 September 2008, and $14^{\text {th }}$ August 2009.

The reactivity of NOM between experiments was compared by using $0.22 \mu \mathrm{m}$ filtered

25 lake water samples that were stored at $-20^{\circ} \mathrm{C}$ directly after sampling. Values for the specific 
50 UV-VIS spectral photometer (Analytic Jena, Germany). Total organic carbon (TOC) analysis was performed with a LiquiTOC DOC Analyser (Elementar Analysensysteme, Germany). NOM concentrations were different on the respective experiment days as indicated by values of $23.3,34.0$, and $28.4 \mathrm{mg} \mathrm{C} \mathrm{L}^{-1}$ in 2006, 2008, and 2009 (Table S1). Respective SUVA $_{254}$ values of 3.3, 3.7, and 4.3 reflect the specific UV absorbance of NOM at $254 \mathrm{~nm}$ and indicate that chemical signature was different between samples (Table S1). Hence reactivity of SW basin water samples may have changed between experiments. Since a direct correlation of SUVA $_{254}$ values, which indicates the specific UV absorbance and photo-reactivity could not be established [5], formation of ${ }^{1} \mathrm{O}_{2}$ and $\mathrm{H}_{2} \mathrm{O}_{2}$ were determined experimentally.

Comparison of water sample photo-reactivity

A direct comparison of ROS formation by artificial irradiation of NOM in water samples was performed with $50 \mathrm{~W} \mathrm{~m}^{-2}$ of UV-A and $1 \mathrm{~W} \mathrm{~m}^{-2} \mathrm{UV}-\mathrm{B}$ (Helarium B1-12-40W, Wolff System, Stuttgart, Germany). This UV light intensity was $\sim 2$-fold higher than the maximum natural UV radiation on a bright summer day at the lake site. UV-A and UV-B light intensities were measured by using respective UV Sensors (Type 2.3 and Type 1.3 for UV-A and UV-B, respectively, Indium Sensors, Neuenhagen, Germany) and a data-logger (LI-1400, LI-COR, Bad Homburg, Germany). Singlet oxygen steady state concentrations were determined according to the method of [6] as described recently [7]. For $\mathrm{H}_{2} \mathrm{O}_{2}$ concentrations the method described by [8] was used with slight modifications: $300 \mu \mathrm{L}$ of $0.22 \mu \mathrm{m}$ filtered water samples were mixed with $9 \mu \mathrm{L}$ freshly prepared Amplex Red Assay consisting of $100 \mu \mathrm{L}$ distilled water and $200 \mu \mathrm{L}$ Horseradish peroxidase (Sigma Aldrich, Seelze, Hannover; $50 \mathrm{U} \mathrm{mL}^{-1}$ in $250 \mathrm{mM}$

49 Tris-HCl, pH7.2), and 2.5 $\mu \mathrm{L}$ Amplex Red (Sigma Aldrich, $1.25 \mathrm{mg} \mathrm{mL}^{-1}$ in DMSO). 50 Fluorescence was measured in a SFM 25 fluorimeter (Kontron, Eiching, Germany) with 51 excitation set to $570 \mathrm{~nm}$ and emission to $585 \mathrm{~nm}$. Alternatively, the Infinite 200 microtiter plate 
reader (Tecan, Männedorf, Switzerland) was used. Blanks were prepared by adding $10 \mathrm{U}$ of catalase (Sigma Aldrich).

Singlet oxygen steady state concentrations were increased by 1.12 and 1.24 -fold in samples from 2008 and 2009 compared to that from 2006. In a similar manner, $\mathrm{H}_{2} \mathrm{O}_{2}$ formation increased by 1.5 and 4.5 -fold, respectively (Table S1). Normalization to DOC concentrations showed that $\left[{ }^{1} \mathrm{O}_{2}\right]_{\mathrm{SS}}$ ranged between 0.55 and $0.73 \times 10^{-14} \mathrm{M}$ per $\mathrm{mg}$ DOC $\mathrm{L}^{-1}$. In contrast, the rate of $\mathrm{H}_{2} \mathrm{O}_{2}$ formation increased from 0.23 to $1.04 \mu \mathrm{M}$ per $\mathrm{mg} \mathrm{DOC} \mathrm{L}^{-1}$ (Table S1). Changes in ${ }^{1} \mathrm{O}_{2}$ and $\mathrm{H}_{2} \mathrm{O}_{2}$ formation were not correlated. Therefore, we conclude that different chemical signatures of NOM may have caused differences in ${ }^{1} \mathrm{O}_{2}$ and $\mathrm{H}_{2} \mathrm{O}_{2}$ formation. Recently published experiments also indicate a limited correlation between ${ }^{1} \mathrm{O}_{2}$ and $\mathrm{H}_{2} \mathrm{O}_{2}$ formation from DOM [9]. The formation of ${ }^{1} \mathrm{O}_{2}$ was not affected by the addition of $10 \mu \mathrm{M} \mathrm{H}_{2} \mathrm{O}_{2}$ to $0.22 \mu \mathrm{m}$ filtered SW basin water samples in 2006 (data not shown). The ratio of $\mathrm{H}_{2} \mathrm{O}_{2}$ generation rate and $\left[{ }^{1} \mathrm{O}_{2}\right]_{\text {ss }}$ determined from UV irradiation experiments was similar in 2006 and 2008, but increased by 2.7 to 3.6-fold in 2009 (Table S1). This clearly indicates that the rate of formation of individual ROS largely depends on the time of sampling and the chemical signature of the NOM present in the lake.

\section{In situ $\mathrm{H}_{2} \mathrm{O}_{2}$ formation and decay}

In situ $\mathrm{H}_{2} \mathrm{O}_{2}$ formation and decay deserved more attention, because $\mathrm{H}_{2} \mathrm{O}_{2}$ concentrations were low compared to similar boreal lakes [10]. In 2006, a decay of 0.68 and $0.28 \mu \mathrm{M} \mathrm{H}_{2} \mathrm{O}_{2} \mathrm{~h}^{-1}$ was observed for unfiltered and $0.22 \mu \mathrm{m}$ filtered surface water samples, respectively. In order to analyse abiotic in situ $\mathrm{H}_{2} \mathrm{O}_{2}$ formation rates, $0.22 \mu \mathrm{m}$ filtered water samples with completely decayed $\mathrm{H}_{2} \mathrm{O}_{2}$ were used. In these samples, a rate of $0.44 \mu \mathrm{M} \mathrm{H}_{2} \mathrm{O}_{2} \mathrm{~h}^{-1}$ was observed during incubation in the surface water layer at $\sim 800 \mathrm{~W} \mathrm{~m}^{-2}$ of sunlight intensity. These findings indicate that $\mathrm{H}_{2} \mathrm{O}_{2}$ generation and degradation is nearly balanced in the $\mathrm{SW}$ basin surface water. 
The use of fresh water samples in 2008 further revealed a rather high $\mathrm{H}_{2} \mathrm{O}_{2}$ degradation capacity even in the absence of bacteria. Water samples were $0.22 \mu \mathrm{m}$ filtered directly after sampling and immediately exposed to sunlight in Whirl-Pak bags. Formation of $\mathrm{H}_{2} \mathrm{O}_{2}$ was only detected at a light dose of $>300$ to $400 \mathrm{~W} \mathrm{~m}^{-2}$ (Fig. S1). This indicates a high $\mathrm{H}_{2} \mathrm{O}_{2}$ degradation capacity which is not directly linked to the activity of bacterial cells.

\section{Potential photochemical effects of unbleached material from the acidic fen area}

Reactivity of NOM in the SW basin is strongly affected by the entry of unbleached NOM from the adjacent fen located in the catchment area next to the SW basin of Lake Grosse Fuchskuhle [11]. To test this hypothesis, ROS formation was investigated in $0.22 \mu \mathrm{m}$ filtered water samples obtained from plastic tubes inserted in the fen area [12]. This unbleached NOM generated 2 to 8 -fold more $\mathrm{H}_{2} \mathrm{O}_{2}$ per mg DOC upon UV-A/B irradiation but similar $\left[{ }^{1} \mathrm{O}_{2}\right]_{\mathrm{SS}}$ concentrations were observed (Table S1). Our results indicate that changes of NOM characteristics due to the entry of unbleached NOM from the fen area strongly affect $\mathrm{H}_{2} \mathrm{O}_{2}$ formation, but only weakly that of $\left[{ }^{1} \mathrm{O}_{2}\right]_{\mathrm{Ss}}$ concentrations. Diurnal values for rainfall and global radiation were plotted for 30 days preceding the respective experiments of 2006, 2008, and 2009 (Fig. S9). However, kinetics of rainfall and global radiation and also the total cumulative amounts of rainfall and radiation for up to 30 days preceding the experiments cannot explain differences in NOM reactivity. Hence, the impact of increased run-off of NOM from the adjacent fen into the SW basin or, in contrast, the prolonged duration of NOM bleaching on the formation of ${ }^{1} \mathrm{O}_{2}$ and $\mathrm{H}_{2} \mathrm{O}_{2}$ in the $\mathrm{SW}$ basin needs to be assessed in greater detail in the future.

\section{Investigation of bacterial community composition by 16S rRNA (gene) based methods}

\section{Differences in experimental procedures}

The experimental set ups varied slightly between the individual experiments. However, in all three experiments the same controls were performed and all data are expressed with reference 
103

to the internal controls. The internal controls included dark incubations of water samples with

104 and without the ${ }^{1} \mathrm{O}_{2}$ photosensitizer Rose Bengal and addition of $\mathrm{H}_{2} \mathrm{O}_{2}$ solution, as well as light exposure without addition of ROS generating chemicals.

The pore size of filter membranes had to be changed after a pilot phase in 2005 and 2006 for technical reasons: serial filtration by using a $5 \mu \mathrm{m}$ pore size syringe disk filter connected to a Sterivex cartirige with $0.2 \mu \mathrm{m}$ pore size saved valuable time for sampling during the experiments. Microscopic inspection of the samples by filtation on $0.22 \mu \mathrm{m}$ membrane filtes followed by Sybr Green I staining, indicated that free-living bacteria were smaller than 1 $\mu \mathrm{m}$ and that particles were mostly larger than $20 \mu \mathrm{m}$. Therefore, the same particles should have been reliably separated from the free-living size fraction irrespective whether filter pore size was 8 or $5 \mu \mathrm{m}$ for serial fitration. This is supported by the very similar DGGE pattern of the free-living fraction in 2006, 2008, and 2009 (Fig. 10 and 11). Also, in all three experiments DGGE patterns of the particle attached fraction clearly differd from those of the free-living fraction (Fig. 10). Thererfore, we are confident that the slight changes in filter pore sizes did not significantly affect the fractionation in our study.

Exclusion of UV light was performed in a larger experimental set up to verifiy the previous finding that UV light does not stongly affect formation of ROS in Lake Grosse Fuchskuhle. UV light is absorbed within the first few $\mathrm{cm}$ in the water column and does not reach the Whirl-Pak bags incubated at $10 \mathrm{~cm}$ (data not shown). The transmission spectra for the Whirl-Pak bags are shown in Fig. S7, which indicate that PP and PE bags do not severely absorbed UV light and that the UV block sheet screend UVA and -B light, but no visible light.

Because all controls were performed for each experiment and relative changes in ${ }^{1} \mathrm{O}_{2}$ and $\mathrm{H}_{2} \mathrm{O}_{2}$ were analyzed with reference to the controls, slight variations in the experimental set up are considered by the overall experimental design. 
Generation and screening of $16 S$ rRNA gene clone libraries

130 Nearly full-length 16S rRNA gene clone libraries were generated for selected treatments with

131 Bacteria primers 8F (5'-AGAGTTTGATCMTGGCTCAG-3') and 1492R (5'-

132 GGYTACCTTGTTACGACTT-3') [13]. PCRs were performed in triplicates in total volumes 133 of $20 \mu \mathrm{l}$ containing $2 \mu \mathrm{L} \mathrm{1:10}$ diluted DNA, $1 \times$ PCR-Buffer, $400 \mu \mathrm{M}$ dNTPs-Mix (Fermentas,

134 St. Leon-Rot, Germany), $0.5 \mu \mathrm{M}$ of each primer, $0.4 \mu \mathrm{g} \mu \mathrm{L}^{-1}$ BSA (Fermentas), and $0.02 \mathrm{U}_{\mu} \mathrm{L}^{-}$

$135{ }^{1}$ Taq DNA polymerase (Qiagen, Hilden, Germany). BSA was added to minimize the inhibition 136 by co-extracted humic substances. PCR amplifications were performed in a Primus 96 Plus 137 cycler (MWG, Ebersberg, Germany) as followed: $95^{\circ} \mathrm{C}$ for $3 \mathrm{~min}, 32$ cycles of $94^{\circ} \mathrm{C}$ for $45 \mathrm{sec}$, $13854^{\circ} \mathrm{C}$ for $45 \mathrm{sec}$, and $68^{\circ} \mathrm{C}$ for $1 \mathrm{~min} 30 \mathrm{sec}$, and finally $68^{\circ} \mathrm{C}$ for $30 \mathrm{~min}$ to increase the $\mathrm{T}$ 139 overhang for TA-cloning. PCRs controlled by agarose-gelelectrophoresis were pooled and 140 purified using a PCR purification kit (Qiagen) and cloned using the Qiagen PCR cloning kit as 141 described by the manufacturer (Qiagen). Screening for positive clones was done by colony142 PCR using plasmid primers M13R (5'-AACAGCTATGACCATG-3') and M13F (-20) (5'143 GTAAAACGACGGCCAGT-3') in a total volume of $10 \mu \mathrm{L}$ including a colony of a clone, $1 \times$ 144 PCR-buffer (Molzym, Bremen, Germany), $400 \mu \mathrm{M}$ dNTP-mix, $0.4 \mu \mathrm{M}$ of each primer, $0.4 \mu \mathrm{g}$ $145 \mu \mathrm{L}^{-1}$ BSA, and $0.02 \mathrm{U}_{\mu} \mathrm{L}^{-1}$ Mol Taq DNA Polymerase (Molzym). PCR cycling conditions 146 were: $95^{\circ} \mathrm{C}$ for $3 \mathrm{~min}, 28$ cycles of $94^{\circ} \mathrm{C}$ for $30 \mathrm{sec}, 55^{\circ} \mathrm{C}$ for $30 \mathrm{sec}$, and $68^{\circ} \mathrm{C}$ for $1 \mathrm{~min} 50$ $147 \mathrm{sec}$, and finally $68^{\circ} \mathrm{C}$ for $15 \mathrm{~min}$. PCR products were controlled by agarose-gelelectrophoresis 148 and PCR with positive inserts were re-amplified by Nested-PCR with cloning primers 8F and $1491492 \mathrm{R}$ in a total volume of $15 \mu \mathrm{L}$ including $0.1 \mu \mathrm{L}$ colony-PCR. PCR and cycling conditions 150 were slightly different as described above: without BSA, an annealing temperature of $54^{\circ} \mathrm{C}$, 151 and a primer extension time of $1 \mathrm{~min}$ and $30 \mathrm{sec}$. Thereafter, PCR products were controlled by 152 agarose-gelelectrophoresis and $5 \mu \mathrm{l}$ of the PCR were either digested with the restriction 153 enzymes HaeIII or RsaI (Fermentas) in a total volume of $10 \mu$ l containing $0.1 \mathrm{U}$ restriction 154 enzyme and $1 \times$ restriction buffer. Samples were digested for $3 \mathrm{~h}$ at $37^{\circ} \mathrm{C}$. PCR amplifications 
and restriction digestions were performed in a C1000 TM Thermal Cycler (Bio-Rad, Munich,

156 Germany) in 96-well microtiter plates. Restriction products were separated in 1.5\% agarose 157 gels in $1 \times$ TBE buffer for $2.5 \mathrm{~h}$ at $3.8 \mathrm{~V} \mathrm{~cm}^{-1}$. For comparison, the $100 \mathrm{bp}$ DNA ladder plus 158 (Fermentas) was loaded three times per gel. EtBr-stained gels were analysed with Gel Compare 159 II version 4.5 (Applied Maths, Sint-Martens-Latem, Belgium) using the unweighted pair group 160 method using arithmetic average (UPGMA) clustering based on the band-based Dice similarity 161 matrix. Operational taxonomic units (OTUs) were defined as the combination of the restriction 162 pattern of HaeIII and RsaI. Approximately 50 clones were investigated for each clone library. 163 Representatives of all OTUs, which occurred more than once in a clone library, were 164 sequenced by the Sanger method from colony-PCRs. Most abundant OTUs were sequenced 165 with plasmid primers from the 5'and 3' ends, whereas less abundant OTUs were only sequenced with the cloning primer $8 \mathrm{~F}$. Furthermore, most abundant OTUs were sequenced

167 from different treatments and years to ensure the sequence identity within an OTU. Sequences 168 were processed manually based on electropherograms using MEGA 5 [14]. A first phylogenetic 169 assignment was done using the RDP II Classifier [15] and BLAST [16]. Chimera checks were 170 performed using the Pintail software [17] and all sequences (and as a consequence respective 171 OTUs) with low pintail values were excluded from the analysis. The coverage of each clone 172 library was determined with the equation $\mathrm{C}=(1-\mathrm{n} / \mathrm{N}) \times 100$, where $\mathrm{N}$ represents the number of 173 investigated clones and $\mathrm{n}$ the number of unique OTUs [18]. Rarefaction curves were generated 174 with Analytic Rarefaction version 2.0 (www.HuntMountainSoftware.com).

\section{$16 S$ rRNA targeting reverse transcriptase (RT)-PCR DGGE analysis}

177 Changes in BCC of metabolically active Bacteria were investigated by 16S rRNA targeting 178 RT-PCR DGGE analysis using primer-systems targeting Bacteria or specific bacterial groups 179 (see below). All used primer-systems and respective amplification conditions are listed in Table 
volume of $15 \mu \mathrm{L}$ including $1.5 \mu \mathrm{L}$ of 1:10 diluted RNA, 5× QIAGEN OneStep RT-PCR buffer, $400 \mu \mathrm{M}$ of each dNTP, $0.4 \mu \mathrm{M}$ of each primer, $0.4 \mu \mathrm{g} \mu \mathrm{L}^{-1} \mathrm{BSA}$, and $0.6 \mu \mathrm{L}$ of the OneStep RT-PCR Enzyme Mix. Quantification of PCR products and DGGE analysis were performed as described previously [7], except DGGE gels were stained with EtBr.

\section{Group-specific $16 S$ rRNA targeting RT-PCR DGGE analysis}

We used group-specific RT-PCR DGGE analysis to investigate the effects of increased $\left[{ }^{1} \mathrm{O}_{2}\right]_{\mathrm{SS}}$ and $\mathrm{H}_{2} \mathrm{O}_{2}$ concentrations on phylotype composition within abundant bacterial groups and focused on the investigation of Actinobacteria, Betaproteobacteria, and Sphingomonadaceae, the most dominant bacterial groups in the SW basin of Lake Grosse Fuchskuhle [19]. Primers used for this approach are listed in Table S4.

We tested three different Betaproteobacteria-specific primer-systems with respect to the amplification specificity and the separation potential of abundant Betaproteobacteria phylotypes on the DGGE gel: (i) Beta680F/GC-1055R, (ii) GC339F/Beta680R, and (iii) GCBeta350F/Beta680R). Betaproteobacteria phylotypes observed by clone library analyses and Betaproteobacteria isolates of relevant groups determined in the SW basin (Polynucleobacter, Limnohabitans-related, Herbaspirillum) were used for the establishment of the Betaproteobacteria-specific primer-systems. The resolution power of the three different Betaproteobacteria-specific primer-systems was tested on DGGE gels after amplification specificity was optimized by gradient-PCRs. Only the primer-system Beta-359F/Beta-680R showed a clear separation of the DGGE bands representing the Betaproteobacteria-OTUs also of very closely related phylotypes. The primer-system showed a high specificity because all sequenced DGGE bands represented Betaproteobacteria (Table 1, Fig. 10). The primer-system was established by [20], where it was only used as a first PCR as template for a Nested-PCR approach for DGGE analysis with universal Bacteria primers. 
For Actinobacteria-specific RT-PCR DGGE analysis we used the primer-system HGC236F/HGC664R [21] that was established for DGGE analysis by [22]. Sequence analysis of selective DGGE bands showed that DNA bands were affiliated to Actinobacteria and mainly under elevated ${ }^{1} \mathrm{O}_{2}$ exposure - also to Verrucomicrobia (Fig. 9). Occasional detection of Verrucomicrobia has been previously observed by [22]. This unspecific amplification did not

211 affect our results in regard to effects of ${ }^{1} \mathrm{O}_{2}$ and $\mathrm{H}_{2} \mathrm{O}_{2}$ on Actinobacteria, because we sequenced 212 all predominant DNA bands.

At first, we also aimed to investigate changes of BCC within the Alphaproteobacteria. Therefore, we tried to use the primer Alf986, which is based on the FISH probe established by [23]. For DGGE analysis we combined this primer with two different Bacteria forward primers, GC-339F and GC-517F. The resolution of DGGE patterns was reasonably good, but sequence analysis of abundant DGGE bands showed that Polynucleobacter sp. (Betaproteobacteria) and Actinobacteria represented the most abundant DGGE bands next to the DGGE band representing $N$. acidiphilum (Alphaproteobacteria) (data not shown). Therefore, instead of investigating all Alphaproteobacteria we focused on the Sphingomonadaceae-specific RT-PCR DGGE analysis (Fig. 10). At first we aimed to use the primer-system Sphingo108F/GC222 Sphingo420R established for Sphingomonadaceae-specific DGGE analysis by [24]. However, 223 the reverse primer used by [24] had two mismatches in the 16S rRNA gene sequence of $N$. acidiphilum, the most abundant Alphaproteobacterium in the south-west basin of Lake Grosse Fuchskuhle. Therefore, we used the Alphaproteobacteria-specific primer ADF689R as reverse primer. Unfortunately, several Novosphingobium type strains did not show a clear separation of 227 DGGE bands and resulted in up to three DGGE bands for one strain. Based on these results, we decided to use a nested-PCR approach with the Sphingomonadaceae-specific primer-system Sphingo108F/Alf968R for pre-amplification and the Bacteria primer-system GC-339F/907R for amplification for DGGE analysis. Different Sphingomonadaceae isolates observed from the

231 SW basin were clearly separated by this approach (data not published). Sequence analysis of 
232 the DGGE bands determined in the Sphingomonadaceae-specific RT-PCR DGGE analysis

233 showed that the major DNA band represented $N$. acidiphilum, whereas all other sequenced

234 DNA bands were affiliated to Alphaproteobacteria other than Sphingomonadaceae. Those

235 unspecific DNA bands occurred only in samples where $N$. acidiphilum seemed to be reduced in

236 abundance as observed by Bacteria-specific DGGE and clone library analysis. In contrast to

237 other Alphaproteobacteria, these sequences represent less abundant phylotypes since they were

238 not observed in any 16S rRNA gene clone library or by Bacteria RT-PCR DGGE analysis.

239 More abundant Alphaproteobacteria determined by Bacteria based analysis were not found.

240 Our results indicate that $N$. acidiphilum was the predominant Sphingomonadaceae species in 241 the SW basin at the time when all experiments were performed. No further 242 Sphingomonadaceae were detected. 


\section{References}

246 1. Baxter RM, Carey JH (1983) Evidence for photochemical generation of superoxide ion in humic waters. Nature 306: 575-576.

2. Cooper WJ (1989) Sunlight induced photochemistry of humic substances in natural waters: major reactive species. Adv Chem Ser 219: 332-362.

3. Zepp RG, Wolfe NL, Baughman GL, Hollis RC (1977) Singlet oxygen in natural waters. Nature 267: 421-423.

4. Cooper WJ, Lean DRS (1989) Hydrogen-peroxide concentration in a northern lake photochemical formation and diel variability. Environ Sci Technol 23: 1425-1428.

5. Weishaar JL, Aiken GR, Bergamaschi BA, Fram MS, Fujii R, et al. (2003) Evaluation of specific ultraviolet absorbance as an indicator of the chemical composition and reactivity of dissolved organic carbon. Environ Sci Technol 37: 4702-4708.

6. Haag WR, Hoigne J (1986) Singlet oxygen in surface waters. 3. Photochemical formation and steady-state concentrations in various types of waters. Environ Sci Technol 20: 341-348.

7. Glaeser SP, Grossart H-P, Glaeser J (2010) Singlet oxygen, a neglected but important environmental factor: short-term and long-term effects on bacterioplankton composition

8. Tranvik L, Kokalj S (1998) Decreased biodegradability of algal DOC due to interactive effects of UV radiation and humic matter. Aquat Microb Ecol 14: 301-307.

9. Dalrymple RM, Carfagno AK, Sharpless CM (2010) Correlations between dissolved organic matter optical properties and quantum yields of singlet oxygen and hydrogen peroxide. Environ Sci Technol 44: 5824-5829.

10. Häkkinen PJ, Anesio AM, Granéli W (2004) Hydrogen peroxide distribution, production, and decay in boreal lakes. Can J Fish Aqua Sci 61: 1520-1527. 
11. Sachse A, Babenzien D, Ginzel G, Gelbrecht J, Steinberg CEW (2001) Characterization of dissolved organic carbon (DOC) in a dystrophic lake and an adjacent fen. Biochemistry 54: $279-296$.

12. Buck U, Babenzien HD, Zwirnmann E (2008) Extracellular peroxidase activity in an experimentally divided lake (Grosse Fuchskuhle, northern Germany). Aquat Microb Ecol 51: 97-103.

13. Lane DJ (1991) 16S/23S rRNA sequencing. In: Stackebrandt E, Goodfellow M, editors. Nucleic acid techniques in bacterial systematics. Chichester: John Wiley. pp. 115-174.

14. Tamura K, Peterson D, Peterson N, Stecher G, Nei M, et al. (2011) MEGA5: Molecular Evolutionary Genetics Analysis Using Maximum Likelihood, Evolutionary Distance, and Maximum Parsimony Methods. Mol Biol Evol 28: 2731-2739.

15. Wang Q, Garrity GM, Tiedje JM, Cole JR (2007) Naive Bayesian classifier for rapid assignment of rRNA sequences into the new bacterial taxonomy. Appl Environ Microbiol 73: 5261-5267.

16. Altschul SF, Gish W, Miller W, Myers EW, Lipman DJ (1990) Basic local alignment search tool. J Mol Biol 215: 403-410.

17. Ashelford KE, Chuzhanova NA, Fry JC, Jones AJ, Weightman AJ (2005) At least 1 in 20 16S rRNA sequence records currently held in public repositories is estimated to contain substantial anomalies. Appl Environ Microbiol 71: 7724-7736.

18. Wilson JB (1991) Methods for fitting dominance diversity curves. J Veg Sci 2: 35-46.

19. Allgaier M, Grossart H-P (2006) Diversity and seasonal dynamics of Actinobacteria populations in four lakes in northeastern Germany. Appl Environ Microbiol 72: 34893497.

20. Mühling M, Woolven-Allen J, Murrell JC, Joint I (2008) Improved group-specific PCR primers for denaturing gradient gel electrophoresis analysis of the genetic diversity of complex microbial communities. ISME J 2: 379-392. 
21. Glöckner FO, Zaichikov E, Belkova N, Denissova L, Pernthaler J, et al. (2000) phylogenetic clusters including an abundant group of Actinobacteria. Appl Environ Microbiol 66: 5053-5065.

22. Allgaier M, Bruckner S, Jaspers E, Grossart HP (2007) Intra- and inter-lake variability of free-living and particle-associated Actinobacteria communities. Environ Microbiol 9: $2728-2741$.

23. Neef, A (1997) Anwendung der in situ-Einzelzell-identifizierung von Bakterien zur Populationsanalyse in komplexen mikrobiellen Biozönosen. Dissertation Technical University of Munich.

24. Leys NM, Ryngaert A, Bastiaens L, Top EM, Verstraete W, et al. (2005) Culture independent detection of Sphingomonas sp EPA 505 related strains in soils contaminated with polycyclic aromatic hydrocarbons (PAHs). Microb Ecol 49: 443-450. 